\title{
Profesi Epidemiologi
}

\section{The Profession of Epidemiology}

\section{Buchari Lapau *}

* Ketua Program Studi Pascasarjana Ilmu Kesehatan Masyarakat STIKes Hang Tuah Pekanbaru, dan Ketua Kolegium Epidemiologi Majelis Kolegium Kesehatan Masyarakat Indonesia.

\begin{abstract}
Abstrak
Makalah ini pertama kali menjelaskan perlu adanya profesi kesehatan masyarakat dalam rangka pembangunan kesehatan. Lalu dijelaskan apa profesi itu dan standar keberadaan profesi, atas dasar mana dapat ditetapkan bahwa pelayanan epidemiologi merupakan salah satu profesi. Dalam rangka pembinaan profesi kesehatan masyarakat, IAKMI dan APTKMI telah membentuk Majelis Kolegium Kesehatan Masyarakat Indonesia (MKKMI) yang terdiri atas 8 kolegium antara lain Kolegium Epidemiologi, yang telah menyusun Standar Profesi Epidemiologi yang terdiri atas beberapa standar. Masing-masing standar dijelaskan mulai dari kurikulum, standar pelayanan epidmiologi, profil epidemiolog kesehatan, peran epidemiolog kesehatan, fungsi epidemiolog kesehatan, standar kompetensi epidemiologi, dan standar pendidikan profesi epidemiologi.
\end{abstract}

Kata Kunci: Kolegium Epidemiologi, Standar Profesi Epidemiologi.

\begin{abstract}
First, this paper explains the need for the public health professional in health development. Furthermore, it is explained what is profession and the standard to be profession; based on the standard, it can be confirmed that epidemiological service is a profession. In the development of public health professional, Indonesian Public Health Association (IAKM) and Indonesian Association of High Education Institute in Public Health (APTKMI) has established the Board of Indonesian Public Health Colleague which consists of 8 colleagues, one of which is the Colleague of Epidemiology producing Professional Standard of Epidemiology. Concerning the professional standard, It is explained curriculum, epidemiological service standard, health epidemiologist profile, the role and functions of health epidemiologist, epidemiological competency standard, and epidemiological professional education standard.
\end{abstract}

Key words: Colleague of Epidemiology, Professional standard of epidemiology

Alamat Korespondensi: Buchari Lapau, Prodi Pascasarjana IKM STIKes Hang Tuah Pekanbaru, Jln. Mustafa Sari No. 5 Tangkerang Selatan Pekanbaru, HP. 081292100225 


\section{Pendahuluan}

Pembangunan kesehatan diarahkan kepada lingkungan yang sehat dan penduduk yang berperilaku sehat yang mampu menjangkau pelayanan kesehatan supaya status kesehatannya terjamin. Dengan demikian Visi dari pembangunan kesehatan adalah supaya masyarakat mandiri untuk hidup sehat, dan Misi pembangunan kesehatan adalah bagaimana membuat masyarakat sehat.

Atas dasar visi dan misi tersebut telah ditetapkan Tujuan Pembangunan Kesehatan, dan Strategi apa yang diperlukan untuk mencapai Tujuan itu. Dari strategi tersebut direncanakan program-program kesehatan, untuk mana diperlukan Sumber Daya Manusia (SDM) di bidang kesehatan yang profesional. Salah satu SDM yang profesional di bidang kesehatan yang diperlukan adalah Ahli Epidemiologi atau Epidemiolog Kesehatan.

Profesi adalah pekerjaan yang didasarkan pada pendidikan/keahlian tertentu sehingga tenaga yang bersangkutan dapat membiayai hidup dari hasil pekerjaan tersebut (Ditjen Pendidikan Tinggi, 2005). Dalam rangka pembangunan kesehatan salah satu sumber daya manusia yang diperlukan adalah Epidemiolog Kesehatan. Yang menjadi pertanyaan adalah apakah Epidemiologi merupakan suatu ilmu atau disiplin ilmu yang di samping bersifat akademis juga bersifat profesional?

Pertanyaan tersebut dapat dijawab dengan adanya standar dari keberadaan profesi yaitu: mempunyai batang tubuh ilmu, standar kompetensi, standar pendidikan, standar pelayanan, kode etik, organisasi profesi tingkat nasional dan organisasi serumpun. Epdemiologi adalah ilmu yang mempelajari kejadian dan distribusi masalah kesehatan dan determinant nya; epidemiologi merupakan metodologi dengan mana dapat dihasilkan informasi ilmiah atau ilmu pengetahuan. Metodolgi dan Ilmu Pengeahuan yang dihasilkan itulah yang disebut Batang Tubuh Ilmu Epidemiologi. Jadi Epidemiologi mempunyai batang tubuh ilmu.

Epidemiologi pada tingkat nasional telah mempunyai organisasi profesi yaitu Perhimpunan Ahli Epidemiologi Indonesia (PAEI) yang didirikan di FKMUI Depok pada tanggal 14 Maret 1989 (Lapau, 2010). Rumpun dari Epidemiologi adalah Ilmu Kesehatan Masyarakat, sedangkan organisasi yang serumpun dengan PAEI adalah Perhimpunan Promosi Kesehatan Inndonesia, dan lain-lain. Jadi jelas bahwa memberikan pelayanan epidemiologi merupakan salah satu pekerjaan profesi. Dalam rangka mempersiapkan epidemiologi sebagai suatu profesi, maka telah dilakukan usaha sistematis seperti dijelaskan dalam seksi-seksi berikut ini.

\section{Kolegium Epidemiologi}

Pada tahun-tahun 2000an telah berkumandang ide bahwa lulusan Fakultas Kesehatan Masyarakat atau Program Studi Sarjana Kesehatan yang menghasilkan Sarjana Kesehatan Masyarakat, baru merupakan fasilitas pendidikan yang bersifat akademis, belum merupakan fasilitas pendidikan yang menghasilkan lulusan profesional. Karena itu sesuai dengan undang-undang dan peraturan yang berlaku di Indonesia, telah direncanakan 
dan dipersiapkan bahwa lulusan yang bergelar Sarjana Kesehatan Masyarakat (SKM) dengan tambahan pendidikan 1 tahun lagi dapat dijadikan Ahli Kesehatan Masyarakat sebagai suatu Profesi Kesehatan Masyarakat Tingkat Pertama. Dalam rangka persiapan tersebut Ikatan Ahli Kesehatan Masyarakat Indonesia (IAKMI) yang bekerja sama dengan Asosiasi Pendidikan Tinggi Kesehatan Masyarakat Indonesia (APTKMI) membentuk Majelis Kesehatan Masyarakat Indonesia (MKKMI).

Pada tanggal tangal 9-10 Mei 2010 di Jakarta diadakan pertemuan nasional waktu mana hadir Pengurus IAKMI Pusat dan Daerah di seluruh Indonesia, demikian pula APTKMI, waktu mana MKKMI ditetapkan terdiri atas 8 kolegium antara lain Kolegium Epidemiologi.

Seperti masing-masing kolegium lain, kewenangan dari Kolegium Epidemiologi adalah sebagai berikut:

1. Menetapkan kurikulum dan program pendidikan

2. Merencanakan dan melaksanakan ujian kepada mereka yang ingin mendapatkan sertifikasi Epidemiolog Kesehatan

3. Menetapkan Lembaga Akreditasi Mandiri yang melakukan akreditasi terhadap institusi yang menyelenggarakan pendidikan profesi epidemiologi kesehatan

4. Membentuk organisasi profesi: sudah berdiri Perhimpunan Ahli Epidemiologi Indonesia (PAEI) di Jakarta sejak 14 Maret 1989

5. Memantapkan sebutan profesi yaitu Epidemiolog Kesehatan

6. Menetapkan institusi yang menyelenggarakan pendidikan profesi
7. Menetapkan Lembaga Sertifikasi Profesi yang perlu bekerja sama dengan Dikti Kemendiknas, BPSDM Kemenkes, BNSP dan Kemenaker

8. Menetapkan sertifikasi dosen epidemiologi.

\section{Program Pendidikan Terkait Epidemiologi}

Untuk mengadakan pendidikan profesi dalam kesehatan masyarakat, tidak terlepas dari pendidikan kesehatan masyarakat menurut jenjangnya yang sudah ada di Indonesia sebagai berikut:

1. Program Pendidikan Sarjana Kesehatan Masyarakat (SKM) yang bersifat akademik generalis, yang memberikan mata ajaran epidemiologi, yang ada pada banyak FKM dari beberapa universitas atau pada Program Studi Sarjana pada banyak STIKes

2. Program Pendidikan SKM dengan Peminatan Epidemiologi yang ada pada beberapa FKM dari beberapa universitas

3. Program Studi Sarjana Epidemiologi, yang ada pada FKM tertentu

4. Program Studi Profesi Ahli Epidemiologi, yang sedang dalam proses pendiriannya dengan bantuan Proyek HPEQ dari Kemdiknas RI

5. Program Studi S2 (Magister) Kesehatan Masyarakat (MKM) Peminatan Epidemiologi

6. Program Studi S2 (Magister) Epidemiologi dengan peminatan Epidemiologi Komunitas, Epidemiologi Klinik dan Epidemiologi Lapangan

7. Program Studi S2 (Magister) Kesehatan Masyarakat MKM) Peminatan Epidemiologi Terapan untuk Manajemen Pelayanan/Program

Kesehatan 
8. Program Studi S3 (Doktor) Kesehatan Masyarakat Peminatan Epidemiologi

9. Program Studi S3 (Doktor) Epidemiologi dengan Peminatan Epidemiologi Komunitas dan Epidemiologi Klinik

\section{Standar Profesi Epidemiologi}

Standar profesi epidemiologi terdiri atas standar-standar sebagai berikut:

1. Standar pelayanan epidemiologi yang meliputi pembinaan dan pemantauan SOP (standard operation procedure) yang dilaksanakan oleh lembaga pelayanan kesehatan baik di jajaran ataupun di luar kementerian kesehatan

2. Standar kompetensi epidemiologi yang dirumuskan atas dasar standar pelayanan epidemiologi

3. Standar pendidikan/pelatihan epidemiologi, di mana dilakukan pembinaan dan pemantauan kurikulum

4. Kode etik, sebagai pedoman bagi para tenaga profesi epidemiologi dalam melaksanakan tugas antara lain berkomunikasi antar sejawat, dengan langgannanya dan dengan masyarakat

\section{Kurikulum}

Pembentukan kurikulum merupakan salah satu kewenangan dari Kolegium Epidemiologi. Kurikulum adalah seperangkat rencana dan pengaturan mengenai isi maupun bahan kajian dan pelajaran serta cara penyampaian dan penilaiannya yang digunakan sebagai pedoman penyelenggaraan kegiatan belajar mengajar di perguruan tinggi. Ada dua pendekatan kurikulum: yang pertama adalah kurikulum berdasarkan isi kurikulum nasional 1994; yang kedua adalah kurikulum berbasis kompetensi yang muncul tahun 2000 (Subdirektorat KPS).

Kurikulum Berbasis Kompetensi (KBK) merupakan tuntutan terhadap perguruan tinggi agar dapat memenuhi kebutuhan masyarakat, industeri, profesi dan pengembangan ilmu untuk generasi masa depan. Ciri-ciri KBK adalah sebagai berikut:

1. Menyatakan kompetensi secara jelas dari proses pembelajaran bidang studinya

2. Proses pembelajaran memberi bekal kepada tercapainya kompetensi dan berfokus pada mahasiswa

3. Lebih mengutamakan kesatuan penguasaan ranah kognitif, psikomotorik dan afektif secara utuh dan terpadu

4. Proses penilaian hasil belajar lebih ditekankan pada kemampuan untuk mendemonstrasikan Kogniif, Psiomotorik dan Afektif (Evaluasi Proses dan Hasil) secara terpadu.

KBK disusun atas dasar Analisis Kebutuhan yang terdiri atas kebutuhan calon mahasiswa ataupun mahasiswa, kebutuhan masyarakat profesi dan kebutuhan ilmu. Kinerja seorang tenaga profesional dikaitkan dengan padanan persyaratan kerja menurut Pilar UNESCO dan Kelompok Mata Kuliah seperti tergambar dalam tabel di bawah ini. 
Tabel 1.

Usaha Pemadanan berbagai Kepentingan

Pada Pengelompokan Mata Kuliah

\begin{tabular}{|c|c|c|}
\hline Persyaratan Kerja & $\begin{array}{c}\text { Empat Pilar Pendidikan } \\
\text { UNESCO }\end{array}$ & $\begin{array}{c}\text { Kurikulum Inti dan } \\
\text { Institusional PT }\end{array}$ \\
\hline $\begin{array}{l}\text { Penguasaan Pengetahuan dan } \\
\text { pengetahuan : } \\
\text { Analisis dan Sintesis } \\
\text { Menguasai IT / Computing }\end{array}$ & Learning to Know & $\begin{array}{l}\text { Mata Kuliah Meilmuan dan } \\
\text { Keterampilan (MKK) }\end{array}$ \\
\hline $\begin{array}{l}\text { Menangani Ambiguity } \\
\text { Oral and Written } \\
\text { Communication } \\
\text { 2nd Language }\end{array}$ & Learning to Do & $\begin{array}{l}\text { Mata Kuliah Keahlian Berkarya } \\
(\mathrm{MKB})\end{array}$ \\
\hline $\begin{array}{l}\text { Sikap : } \\
\text { Kepemimpinan } \\
\text { Team Work } \\
\text { Can Work Crossculturally }\end{array}$ & Learning to $\mathrm{Be}$ & $\begin{array}{l}\text { Mata Kuliah Perilaku berkarya } \\
\text { (MPB) }\end{array}$ \\
\hline $\begin{array}{l}\text { Pengenalan sifat pekerjaan terkait: } \\
\text { Terlatih dalam Etika Kerja } \\
\text { Memahami makna Globalisasi }\end{array}$ & Learning to Live Together & $\begin{array}{l}\text { Mata Kuliah Berkehidupan } \\
\text { Bermasyarakat (MBB) }\end{array}$ \\
\hline $\begin{array}{l}\text { Fleksible Terhadap Pilihan } \\
\text { Pekerjaan }\end{array}$ & & $\begin{array}{l}\text { Mata Kuliah Pengembangan } \\
\text { Keperibadian (MPK) }\end{array}$ \\
\hline
\end{tabular}

Dalam tabel tersebut di atas terlihat bahwa 4 Pilar UNESCO sepadan dengan 4 Mata Kuliah yaitu MKK, MKB, MPB dan MBB. Di samping itu ada lagi satu Mata Kuliah Pengembangan Kepribadian (MPK). Kesepadanan tersebut dapat dijelaskan sebagai berikut:

1. Pilar Learning To Know seimbang dengan Mata Kuliah Keilmuan dan Keterampilan (MKK) yang memenuhi Persyaratan Kerja dengan Kompetensi untuk menganalisis dan mensintesis dan menguasai teknologi informasi dan komputerisasi

2. Pilar Learning To do seimbang dengan Mata Kuliah Keahlian Berkarya (MKB) yang memenuhi Persyaratan Kerja dengan Kompetensi menangani risiko dan mampu berkomunikasi secara tertulis ataupun secara oral termasuk dapat menggunakan bahasa asing
3. Pilar Learning To Be seimbang dengan Mata Kuliah Perilaku Berkarya (MPB) yang memenuhi Persyaratan Kerja dengan Kompetensi yang berkaitan dengan Sikap yaitu kepemimpinan, bekerja dalam Tim dan dapat bekerja lintas budaya

4. Pilar Learning To Live Together seimbang dengan Mata Kuliah Berkehidupan Bermasyarakat (MBB) yang memenuhi Persyaratan Kerja dengan kompetensi terlatih dalam etika kerja, memahami makna globalsasi dan fleksibel terhadap pilihan pekerjaan.

Atas dasar 4 pilar UNESCO dan tambahan 1 pilar lagi itu, maka disusunlah Pedoman Penyusunan Kurikulum Perguruan Tinggi sesuai dengan Surat Keputusan Mendiknas RI No. 045/U/2002 seperti pada tabel 2. 
Tabel 2.

Pedoman Penyusunan Kurikulum PT Sesuai SK MENDIKNAS RI no. 045/U/2002

\begin{tabular}{|c|c|c|c|}
\hline \multirow[t]{2}{*}{ Elemen Kompetensi } & \multirow{2}{*}{$\begin{array}{c}\begin{array}{c}\text { Kurikulum } \\
\text { Inti }\end{array} \\
\text { Kompetensi } \\
\text { Utama }\end{array}$} & \multicolumn{2}{|c|}{ Kurikulum Institusional } \\
\hline & & $\begin{array}{l}\text { Kompetensi } \\
\text { Pendukung }\end{array}$ & $\begin{array}{l}\text { Kompetensi } \\
\text { Lainya }\end{array}$ \\
\hline Landasan Keperibadian & \multirow{5}{*}{$40 \%-80 \%$} & \multirow{5}{*}{$20 \%-40 \%$} & \multirow{5}{*}{$10 \%-30 \%$} \\
\hline Penguasaan ilmu dan Keterampilan & & & \\
\hline Komponen Berkarya & & & \\
\hline Sikap dan Perilaku dalam Berkarya & & & \\
\hline $\begin{array}{lll}\begin{array}{l}\text { Pemahaman } \\
\text { bermasyarakat }\end{array} & \text { Kaidah } & \text { Berkehidupan } \\
& & \end{array}$ & & & \\
\hline
\end{tabular}

Dalam tabel tersebut di atas bahwa 4 pilar UNESCO dan 1 pilar lagi itu merupakan Elemen Kompetensi yang didistribusikan menjadi 1) Kuriklum Inti yang berisi Kompetensi Utama 40\% $80 \%$, dan 2) Kurikulum Institusional yang berisi Kompetensi Pendukung 20\% - 40\% dan Kompetensi lainnya 0\% - 30\%.

\section{Standar Pelayanan Epidemiologi}

Seperti telah dijelaskan di atas bahwa Standar Kompetensi didasarkan antara lain pada Satandar Pelayanan. Dalam makalah ini Standar Pelayanan Epidemiologi mengacu pada Tugas Pokok dan Rincian Kegiatan Tenaga Jabatan Fungsional Epidemiologi yang telah ditetapkan oleh Departemen Kesehatan sebagai berikut (Perhimpunan Ahli Epidemiologi Indonesia, 2010):

1. Melakukan persiapan pelaksanaan kegiatan

2. Melakukan surveilens epidemiologi

3. Melakukan penyelidikan atau wabah

4. Melakukan sistem kewaspadaan dini

5. Melakukan pencegahan dan pemberantasan penyakit

6. Melakukan pemberdayaan masyarakat

\section{Profil Epidemiolog Kesehatan}

Atas dasar Standar Pelayanan dan batang tubuh ilmu epidemiologi, maka dalam satu pertemuan yang diadakan oleh PAEI (Perhimpunan Ahli Epidemiologi Indonesia) telah ditetapkan Profil Epidemiolog Kesehatan yang mempunyai kemampuan untuk berperan sebagai berikut:

1. Melakukan identifikasi dan pemecahan masalah

2. Merencanakan, melaksanakan dan menilai sistem surveilens

3. Merencanakan, melaksanakan dan pemantauan kewaspadaan dini

4. Merencanakan dan melakukan penyelidikan Kejadian Luar Biasa (KLB) atau wabah

5. Merencanakan, melaksanakan, memantau dan menilai program kesehatan termasuk peogram pemberantasan penyakit menular

6. Merencanakan dan melaksanakan manajemen/audit

7. Merencakan, melaksanakan dan menilai pendidikan dan pelatihan dan pemberdayaan masyarakat alam rangka surveilens.

8. Menguasai teknologi informasi 
Peran-peran tersebut di atas yang dalam tabel 3. berikut ini: didistribusikan menurut Kurikulum terlihat

Tabel 3.

Profil Epidemiolog Kesehatan Menurut Peran, Kurikulum Inti dan Kurikulum Institusional

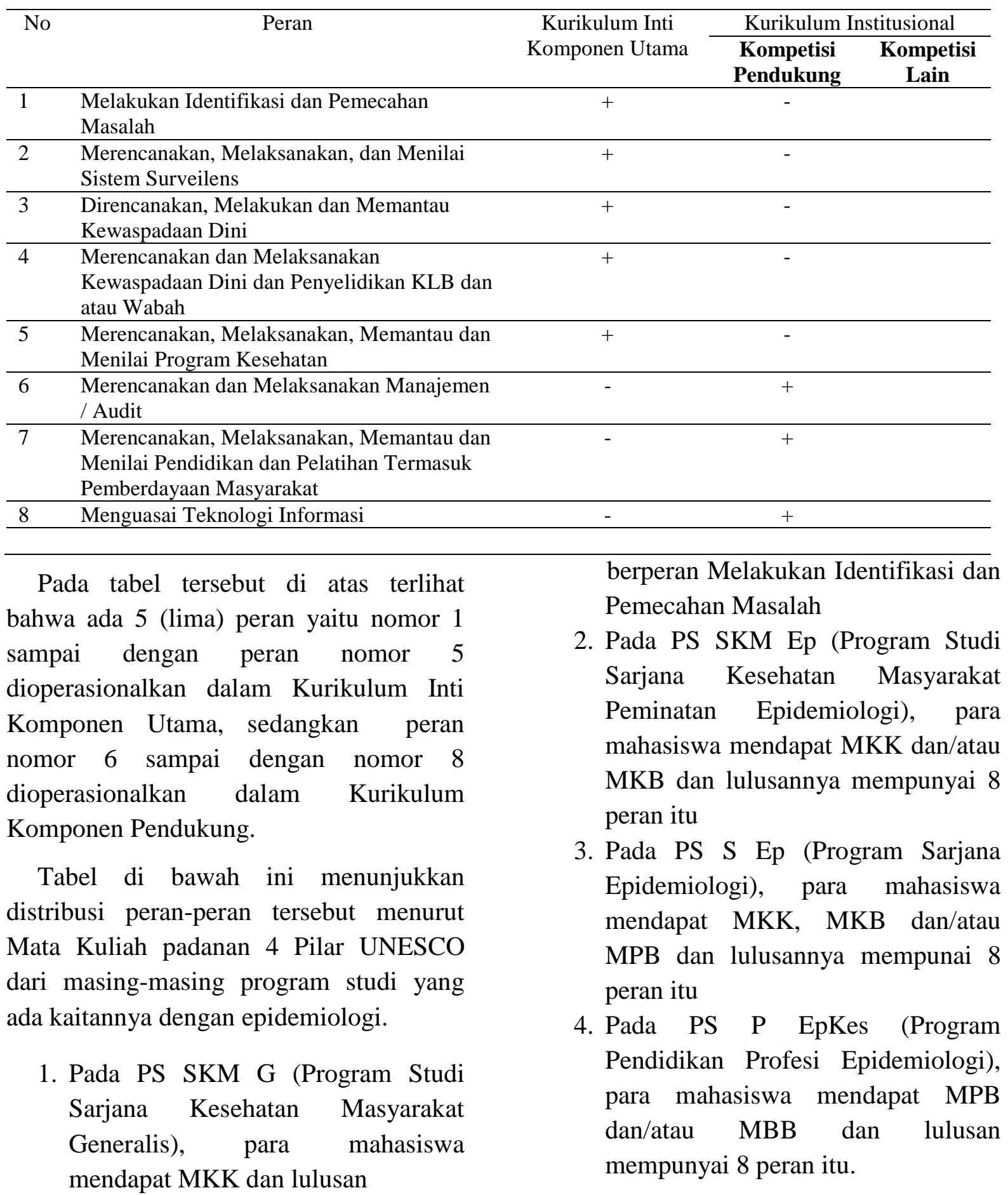


Tabel 4.

Distribusi Peran Epidemiologi Menurut Program Studi Dan Kelompok Mata Kuliah

\begin{tabular}{|c|c|c|c|c|}
\hline \multirow[t]{2}{*}{ Peran } & \multicolumn{3}{|c|}{ Program Studi Asal } & \multirow[t]{2}{*}{ PSP. Epkes } \\
\hline & $\begin{array}{l}\text { PS SKM } \\
\text { G }\end{array}$ & PS SKM EP & PS S Ep & \\
\hline \multirow[t]{2}{*}{ Melakukan Identifikasi dan Pemecahan Masalah } & MKK & MKK & MKK & MPB \\
\hline & & MKB & MKB & MBB \\
\hline \multirow{2}{*}{$\begin{array}{l}\text { Merencanakan, Melaksanakan dan menilai sistem } \\
\text { surveilens }\end{array}$} & & MKB & MKB & MKB \\
\hline & & MPB & MPB & MPB \\
\hline \multirow{2}{*}{$\begin{array}{l}\text { Merencanakan, melaksanakan, dan memantau } \\
\text { kewaspadaan dini }\end{array}$} & & MKB & MKB & MPB \\
\hline & & & MPB & MBB \\
\hline \multirow{2}{*}{$\begin{array}{l}\text { Merencanakan atau melaksanakan penyelidikan KLB } \\
\text { atau wabah }\end{array}$} & & MKB & MKB & MPB \\
\hline & & & MPB & MBB \\
\hline \multirow{2}{*}{$\begin{array}{l}\text { Merencanakan, melaksanakan, memantau dan } \\
\text { menilai program kesehatan }\end{array}$} & & MKB & MKB & MPB \\
\hline & & & MPB & MBB \\
\hline \multirow[t]{2}{*}{ Merenanakan dan melaksanakan manajemen / audit } & & MKB & MKB & MPB \\
\hline & & & MPB & MBB \\
\hline $\begin{array}{l}\text { Merencanakan, melaksanakan, memantau dan } \\
\text { menilai pendidikan dan pelatihan termasuk } \\
\text { pemberdayaan masyarakat. }\end{array}$ & & MKB & MKB & MPB \\
\hline Menguasai teknologi Informasi & MKK & $\begin{array}{l}\text { MKK } \\
\text { MKB }\end{array}$ & & \\
\hline Standar Kompetensi Epidemiologi & $\begin{array}{l}\text { me } \\
\text { ter }\end{array}$ & $\begin{array}{l}\text { ebabkan } \\
\text { ut dalam bu }\end{array}$ & $\begin{array}{l}\text { resenjang } \\
\text { r atas. }\end{array}$ & \\
\hline $\begin{array}{l}\text { Pada halaman-halaman sebelumnya } \\
\text { telah dijelaskan Profil Epidemiolog } \\
\text { Kesehatan yang mempunyai } 8 \text { Peran. } \\
\text { Setiap Peran terdiri atas beberapa Fungsi, } \\
\text { dan setiap fungsi terdiri atas beberapa }\end{array}$ & $\begin{array}{l}\text { 3. Mar } \\
\text { mas } \\
\text { 4. Mar } \\
\text { fakt } \\
\text { tuju }\end{array}$ & $\begin{array}{l}\text { pu menentuk } \\
\text { lah atas dasa } \\
\text { pu menen } \\
\text { informasi y } \\
\text { a seperti pad }\end{array}$ & $\begin{array}{l}\text { in tujuan } \\
\text { butir diat } \\
\text { ukan d } \\
\text { ng berka } \\
\text { butir } 3 \text {. }\end{array}$ & $\begin{array}{l}\text { dentifikasi } \\
\text { s. } \\
\text { ta atau } \\
\text { an denga }\end{array}$ \\
\hline
\end{tabular}

Kompetensi (Slamet, blogspot.com).

Peran untuk mengidentifikasi dan memecahkan masalah kesehatan bersama dalam satu tim.

Dalam peran ini, epidemiologi kesehatan mempunyai fungsi-fungsi sebagai berikut: Menyiapkan rencana untuk mengidentifikasi masalah kompetensi yang harus dimiliki:

1. Mampu mengetahui kesenjangan antara apa yang diharapkan dengan apa yang terjadi, atau antara apa kebijaksanaan / perecanaan dan pelaksanaan.

2. Mampu mengidentifikasi faktor atau kondisi/situasi yang mungkin

5. Mampu menentukan jenis data (Primer, sekunder), informasi/ fakta yang tersebut pada butir4.

6. Mampu menentukan sumber data atau fakta/informasiyang terdapat dalam butir 4 .

7. Mampu menentukan cara pengumpulan (wawancara tersetruktur, wawancara bebas, wawancara berfokus, observasi saja, observasi partisipasi, diskusi kelompok berfokus, dan analisis isi bahan tertulis partisipasi) data yang tersebut pada butir 4 .

8. Mampu merencanakan ala pengumpulan data (kuisioner, angket, cheklist, lembaran jawaban, dan lainlain) yang tersebut pada butir 4 . 


\section{Standar Pendidikan}

Seperti terlihat pada gambar di bawah ini, Output yaitu lulusan dari suatu Pendidikan Profesi tergantung pada Proses Belaja Mengajar (BM), yang juga tergantung pada 1) Input Mahasiswa, 2) Software Input yang antara lain Dosen, Instrktur, Mata Kuliah termasuk kurikulumnya, 3) Hardware Input termasuk gedung, ruang kelas, ruang laboratorium, daerah binaan, alat-alat, transportasi, dan lai-lain, dan 4) External Input termasuk bantuan dalam negeri (Kemendiknas, Kemenkes, Kemenker, dll) dan luar negeri (universitas, dll).

Gambar 1.

Standar Pendidikan Profesi Pendidikan Sebagai Sistem

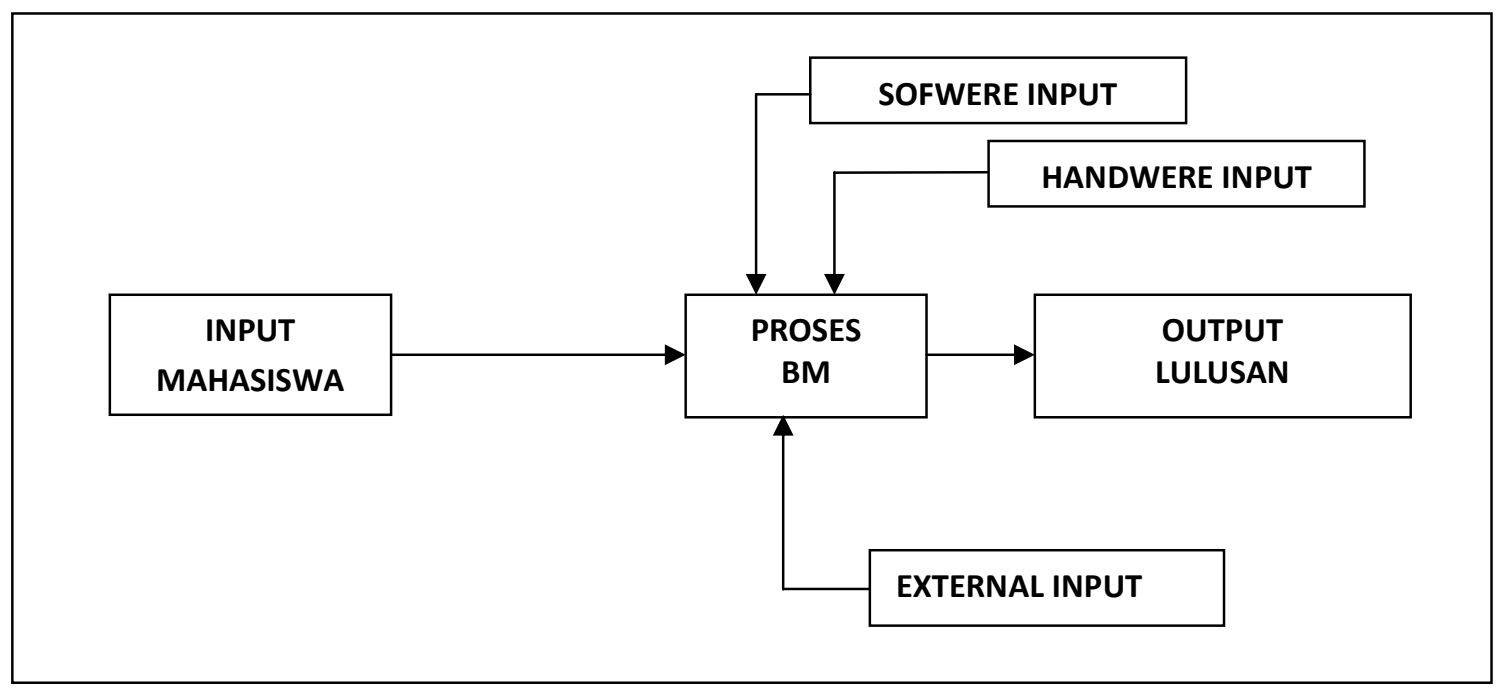

\section{Daftar Pustaka}

Dit. Jen. Pendidikan Tinggi. Kemendiknas .2010 Kurikulum Berbasis Kompetensi, Jakarta: Dit.Jen. Pendidikan Tinggi.

Lapau, Buchari. 2010 Prinsip dan Metode Epidemiologi, Jakarta: Balai Penerbit FKUI.

Lapau, Buchari. 2010 Sejarah Perkembangan PAEI, info paei, blogspot.com

Perhimpunan Ahli Epidemiologi,2010 Indonesia. Standar Profesi Epidemiologi, Jakarta: PAEI
Slamet, Margono. Kurikulum Perguruan Tinggi Berbasis Kompetensi yang disajikan di Universitas Riau, eng. Unri. Blogspot.com

Subdirektorat KPS. Panduan Kurikulum Berbasis Kompetensi Pendidikan Tinggi (sebuah alternatif penyusunan kurikulum), Jakarta: Direktorat Akademik, Dit. Jen Pendidikan Tinggi 
